\title{
COMPARAÇÃO DA CONCENTRAÇÃO DE METAIS PESADOS NAS ÁGUAS DO RIO SÃO FRANCISCO EM TRÊS MARIAS, DESDE 1991 ATÉ HOJE, RELACIONANDO A ATUAÇÃO DA CMM-TRÊS MARIAS.
}

\author{
Mara Regina de Oliveira ${ }^{1} \&$ Adolf Heinrich Horn ${ }^{1}$
}

\begin{abstract}
The aim was to evaluate some heavy metals contamination level $(\mathrm{Zn}, \mathrm{Cd}, \mathrm{Pb})$ and water $\mathrm{PH}$ on $\mathrm{São}$ Francisco river in Tres Marias, between the CEMIG dam and Barra do Retiro Velho, an area under CMM (Companhia Mineira de Metais) influence, comparing concentration values in 1991 and 2003/ 2006. Sample waters were collected from some places once contaminated by CMM - Companhia Mineira de Metais, which, for years, since it begins operating in 1969, threw all industrial efluents in natura in São Francisco River. In 1991 Fachoschule München students researched the CMM surrounding area and found high values of heavy metals on water. Water sampling followed Standard Methods for the Water and Wastewater (APHA 1992) and Sample waters Collect and Preservation Guide from CETESB (1988) and were performed in 4 sampling campaigns. Metals contents were analised by ICP-AES on IGC/UFMG Research Centre and conductivity and PH were measured in situ by Digimed, DM 20 device. ZN concentraction leval was above legal level on sample points took in waters of Barreiro Grande brook and São Francisco river, soon after the water returning point, on left bank and on Consciência brook confluence, which value is 25 times higher than the limit established by CONAMA 357. In comparison with sampled points in 1991, we had then much more elevated values, because CMM does not take care about its effluents deposition. $\mathrm{ZN}, \mathrm{Cd}$ and $\mathrm{Pb}$ had high concentrations on CMM influence area, on the river right bank, this means, in points that receive direct effluents from CMM, and more distant points on the same bank, showing that these metals are carried in soluble form, before precipitating with sediment. After Consciência brook, Zn level gradually diminishes. One can conclude that CMM's use of a more appropriate effluent treatment led to a level reduction of these metals on superficial waters, what is indicated by data interpretation. Nevertheless, we must remember that metals on sediments are still present on the area, as it precipitate among organic matter, clay minerals and $\mathrm{Fe}$ and $\mathrm{Mn}$ oxids and hydroxids, and can suffer ressobilization to water form with changing of physical-chemical water conditions - PH changes, for instance.
\end{abstract}

Keywords: água, metais pesados, Rio São Francisco.

\section{INTRODUÇÃO}

Elementos que ocorrem no ambiente em concentrações muito baixas, de partes por milhão ou até menos, são normalmente chamados de elementos traços. Alguns destes elementos são reconhecidos como nutrientes requeridos por animais ou plantas. Destes, alguns são essenciais à baixas concentrações, mas tóxicos sob altos níveis de concentrações.

Os metais diferenciam-se dos compostos orgânicos tóxicos por serem absolutamente não degradáveis, de maneira que podem acumular-se nos componentes do ambiente onde manifestam sua toxidade.

$\mathrm{Na}$ natureza os metais pesados constituem menos que $1 \%$ da composição da litosfera e são elementos traços, na geoquímica. Os macro elementos $(\mathrm{O}, \mathrm{Si}, \mathrm{Al}$, $\mathrm{Fe}, \mathrm{Ca}, \mathrm{Na}, \mathrm{K}, \mathrm{Mg}, \mathrm{Ti}, \mathrm{H}, \mathrm{P}, \mathrm{e} \mathrm{S}$ ) compreendem os $99 \%$ restantes. Esses elementos traços ocorrem como impurezas em substituições isomórficas de vários macroelementos constituintes da rede cristalina de muitos minerais primários, ou no rearranjo dos elementos nos minerais secundários, os quais são produtos do intemperismo dos minerais primários.

Embora sejam comuns na natureza, as atividades humanas têm contribuído para um certo aumento do nível dos metais pesados em muitos dos ecossistemas aquáticos naturais, destacando-se as indústrias e as minerações.

As indústrias, segundo Jardim (1983) e Macedo (2002), são as principais fontes poluidoras de origem antropogênica e a forma mais comum de contaminação é através da descarga de efluentes não devidamente tratados nos recursos hídricos, apesar de a eliminação de partículas na atmosfera ser, em muitos casos, o principal veículo poluidor.

Outras fontes de metais pesados que contribuem, porém em menor escala, para o aumento da mobilidade dos metais pesados no ambiente aquático são os efluentes de esgotos, incineradores de lixo urbano e industrial, partículas em suspensão na atmosfera e suas precipitações, e a atividade agrícola (Jardim, 1983).

Com a crescente contribuição antropogênica na 
liberação de metais para os corpos d'água, verifica-se um enriquecimento destes constituintes, nestes sistemas, o que gera uma preocupação no sentido de toxicidade inerente (biodisponibilidade), ou seja, a capacidade destes elementos químicos serem incorporados por organismos (inclusive o homem) que direta ou indiretamente estão em contato com ou fazem uso dos recursos hídricos, (Forstner \& Wittmann, 1981). Sendo a água o principal meio de transporte destes elementos no sistema aquático, e funcionando também como veículo transmissor da contaminação, através do qual o homem pode ser contaminado, é fundamental a monitoração dos níveis de concentração dos metais pesados na água e análises que permitam conhecer seus comportamentos no meio aquoso, objetivando a avaliação do risco a eles associados.

Desta maneira este trabalho tem como objetivo apresentar uma correlação entre os níveis de concentração de alguns metais pesados e do $\mathrm{pH}$ na água, investigados em 1991 e em 2003/2006, no rio São Francisco, em Três Marias, entre a represa da CEMIG e a Barra do Retiro Velho, área de influência da Companhia Mineira de Metais, CMM. A análise consiste em se estabelecer uma relação com a mudança no controle da disposição de efluentes no ambiente, pela CMM, devido ao incremento da legislação ambiental e também associar os níveis destes metais a outros parâmetros investigados na água.

\section{CONTEXTUALIZAÇÃODOPROBLEMA}

Para entender melhor o fato estudado é importante conhecer desde o começo, ou desde a época da chegada na CMM em Três Marias, alguns dados que foram levantados na época sobre os metais pesados no rio São Francisco.

Em janeiro de 1961, foi concluída a construção da Barragem de Três Marias a partir do represamento do Rio São Francisco. Teve como principais objetivos: regularização do curso das águas do rio nas cheias periódicas; melhoria da navegabilidade; utilização do potencial hidrelétrico e o fomento da indústria e irrigação.

Em 1963, o município obteve sua emancipação e contava com poucos habitantes. Em 1965, foi iniciada a construção das instalações da Companhia Mineira de Metais - CMM, atual Votorantim Metais Zinco SA Três Marias. Em 1969, a CMM iniciou sua operação, lançando seus rejeitos industriais diretamente, in natura, no rio São Francisco.

Em 1973, o Departamento Nacional de Águas e Esgotos - DNAEE apontou a CMM como responsável pela poluição do rio São Francisco e pelo lançamento de grandes quantidades de material tóxico em suas águas (CETEC, 1980). Nessa mesma data, o Centro Tecnológico de Minas Gerais - CETEC constatou estagnação das águas do ribeirão Consciência, afluente do Rio São Francisco, localizado a jusante da CMM, durante os períodos de chuvas, mencionando que quando havia uma elevação do nível de água no rio São Francisco, o ribeirão Consciência passava a funcionar como uma bacia de sedimentação, com acumulação de grandes quantidades de sedimentos (CETEC, 1980). ?Em 1974, o DNAEE relatou que o $\mathrm{pH}$ na desembocadura do ribeirão Consciência atingia o valor de 3,0, indicando a natureza ácida dos efluentes da CMM e que o teor de zinco, cádmio e cobre de suas águas alcançavam, respectivamente, os valores de 560,0; 0,17 e 7,2 mg/L. Além disso, a medida da condutividade elétrica foi de 4.600,0 mho/cm (CETEC, 1980).

Em 1976, a Companhia de Pesquisa de Recursos Minerais - CPRM, em seu relatório, afirma que o ribeirão Consciência passou a ser o próprio despejo da CMM, só não atingindo proporções drásticas por causa do grande volume de água do rio São Francisco com sua conseqüente capacidade de diluição.

Em out/1978, o COPAM (CETEC, 1980) afirma que as lamas, depositadas nos terrenos da CMM, não só poluem os solos, mas também o rio São Francisco. As fortes chuvas carreiam grandes quantidades de lamas residuárias para o rio São Francisco provocando mortandade de peixes.

Em 1983, a Barragem de contenção situada às margens do rio São Francisco, denominada atualmente de Barragem Velha, entrou em funcionamento.

A CMM hoje é líder mundial na produção de zinco a partir de minério silicatado, com participação de $65 \%$ no mercado nacional. As minas de Vazante e de Morro Agudo são responsáveis pelos concentrados de silicatados e sulfetados, respectivamente, que abastecem a planta metalúrgica de Três Marias. Os principais produtos são o óxido de zinco, ligas, lingote, Zn líquido, pó de zinco e ácido sufúrico. Com sua localização estratégica, como é possível ver na figura 1, às margens do rio e da rodovia que liga as cidades de Brasília a Belo Horizonte, a CMM vem aumentando sua produção ao longo dos anos.

$\mathrm{Na}$ figura 2 visualiza-se o processo usado pela $\mathrm{CMM}$, hoje, para o refino do material oriundo das Minas de Vazante e Morro Agudo. Depois de processos de separação e enriquecimento do zinco e com a produção do $\mathrm{H}_{2} \mathrm{SO}_{4}\left(\mathrm{SO}_{2} / \mathrm{O}_{2} / \mathrm{H}_{2} \mathrm{O}\right)$ através do tratamento do mineral sulfetado pela flotação e decantação, o resíduo é depositado numa estação de tratamento de pH 9.

Para o processamento do zinco, a CMM utiliza água do rio São Francisco, utilizando-a também no resfriamento e refrigeração, produção de vapor e consumo humano (sanitários e restaurante). A água bruta do São Francisco entra no processo de clarificação para as remoções das matérias muito finas, sólidos suspensos e impurezas resultantes do contato com o ar e a terra, que depois de passar pelo processo convencional de tratamento de água, como a coagulação, floculação e decantação, esta água retorna para o mesmo rio.

Os efluentes líquidos são principalmente os industriais e esgotos sanitários. Os primeiros passam por uma estação de tratamento de efluentes industriais antes de irem para o rio São Francisco. O esgoto sanitário 
juntamente com o esgotamento do refeitório é tratado pelo sistema de fossas sépticas. O lodo gerado no tratamento dos sanitários segue para as lagoas de bioacumulação. Posteriormente tudo retorna para o rio São Francisco e córrego Barreiro Grande.

As aguas pluviais que não estão em contato com a unidade industrial deságuam no córrego Barreiro Grande. Outros locais, como a hidrometalurgia, ustulação e fábrica de ácidos tem suas águas pluviais encaminhadas para um tanque de onde são bombeadas para o sistema de tratamento de efluentes líquidos industriais. As emissões atmosféricas são os SOx e material particulado através das chaminés que possuem como sistema de controle os filtros de mangas.

Durante a produção há possibilidade de contaminação do ar pela poeira, como da água pelo efluente da planta industrial, causada pela lixiviação da fumaça, refrigeração e clarificação da água (Companhia Mineira de Metais - CMM, 2003).

Estudos anteriores realizados por alunos da "Fachhochschule München" em 1991 na região da represa e da zona de influência da CMM, no rio São Francisco, constataram índices de metais pesados que variavam com o tipo de atividade instalada nas margens do rio, revelando a grande influência antrópica na qualidade da água. Também no final da década de 90, a organização Greenpeace apontou em Três Marias, a ocorrência, em 1999, de contaminação pelos elementos $\mathrm{Zn}, \mathrm{Cd}, \mathrm{Cu}$ e $\mathrm{Pb}$, tendo como causa as áreas de deposição de resíduos de metalurgia (Greenpeace, 2002). Sabe-se que, recentemente, algumas medidas mitigadoras foram adotadas para reduzir ao máximo os impactos verificados naquela época, principalmente pela CMM, em função da adequação ao sistema de licenciamento ambiental realizado pela Fundação Estadual do Meio Ambiente em Minas Gerais. Nos anos anteriores a 2001, a CMM depositava seu rejeito diretamente sobre o solo, ocasionando a lixiviação dos metais para zonas mais profundas no solo, e conseqüente contaminação do lençol freático e as águas do rio São Francisco (CETEC, 1980).

\section{DESCRIÇÃODAÁREA}

O clima da área apresenta temperatura média anual de cerca $24^{\circ} \mathrm{C}$, com predominância de temperaturas elevadas na região durante quase todo o ano. Com

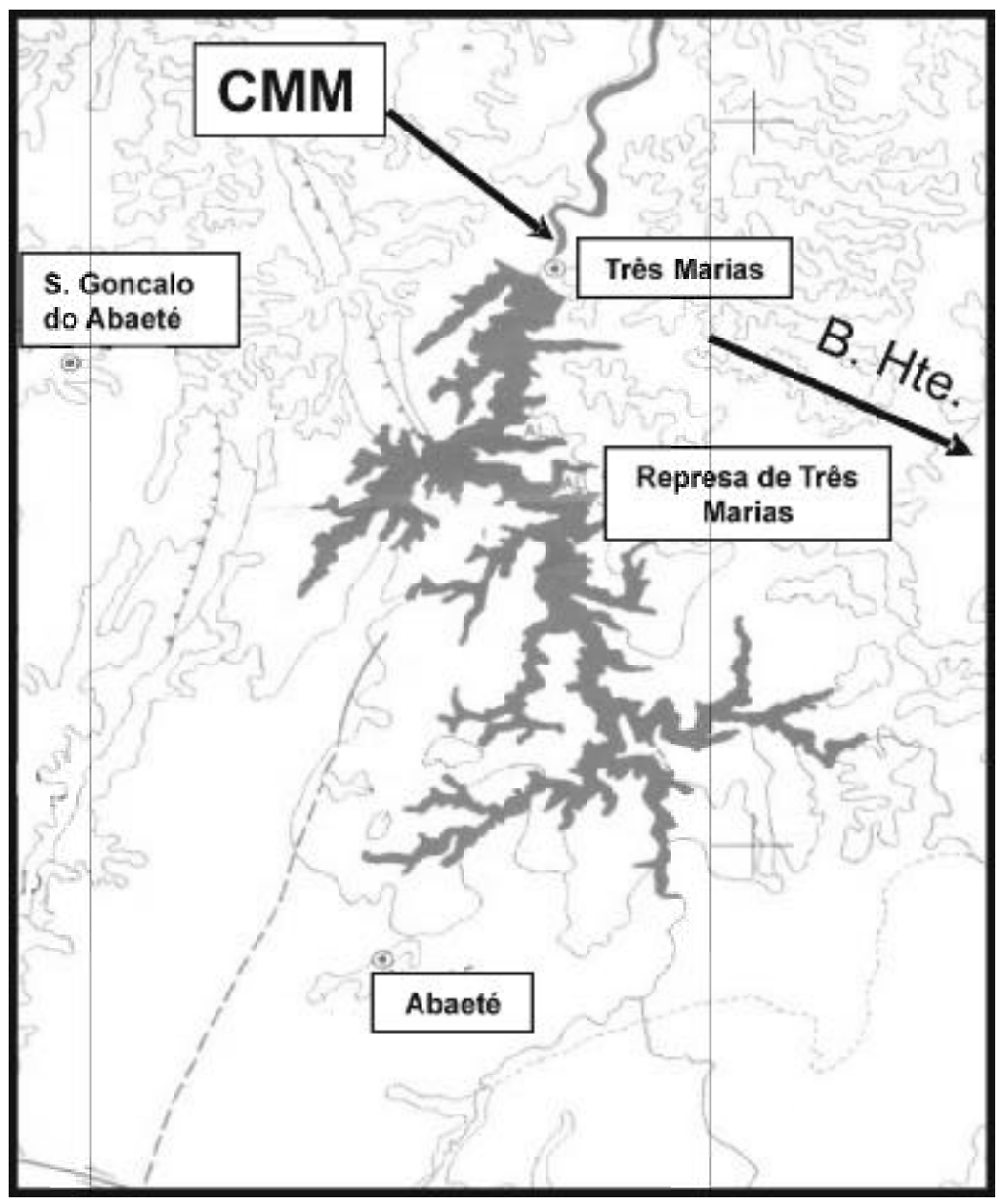

Fig 1 : Localização da barragem de Três Marias e sua contextualização dentro do estado de Minas Gerais. 
relação às precipitações, os totais pluviométricos anuais são em média $1.022 \mathrm{~mm}$, com regime pluviométrico típico das regiões de clima tropical, tendo escomento superficial de 13,5 1/s a cada $\mathrm{km}^{2}$, correspondendo a $30 \%$ das chuvas. Até o início da década de 80 a vazo média anual em Três Marias, em 19 anos de registro, foi de $654 \mathrm{~m}^{3} / \mathrm{s}$, sendo o ano mais seco o de 1954, com vazão média de $315 \mathrm{~m}^{3} / \mathrm{s}$ (Euclydes \& Ferreira, 2001). A região se enquadra na tipologia climática de Köppen, como Aw, clima tropical chuvoso, quente e úmido, com inverno seco e verão chuvoso (Menezes et al., 1978).

O relevo da região é caracterizado como plano e com algumas áreas dissecadas resultantes de processos morfoclimáticos associados ao condicionamento geológico. Assim, a área está inserida na Depressão São Franciscana (Euclydes \& Ferreira, 2001). A vegetação nativa da região é constituída predominantemente pelo cerrado, constituindo-se principalmente de gramíneas, arbustos e árvores de médio porte. São comuns na região as ocorrências de veredas. Atualmente nas regiões mais planas, o cerrado vem sendo substituído por pastagens e áreas de cultivo mecanizado, ou mesmo devastadas para a prática de silvicultura.

Quanto ao tipo de solo da região o CETEC (1983) classificou o solo da área como cambissolo: com A moderado, textura média a argilosa; e solos litólicos: com A fraco e moderado, textura indiscriminada; ambos distróficos. Estes solos apresentam baixa fertilidade natural que aliada a falta d'água e a susceptibilidade a erosão, limitam sua utilização.

A região estudada possui litologias da Formação Três Marias descritas por Chiavegatto (1992) como uma seqüência de arcózios cinzas de granulometria predominantemente muito fina a fina, intercalados com siltitos cinza-esverdeados e/ou violáceos. A Formação Três Marias é recoberta discordantemente, de forma erosiva, pela Formação Areado (Cretáceo Inferior) e por depósitos sedimentares cenozóicos indiferenciados.

As amostras de água coletadas no rio São Francisco no ano de 2003 à 2006, foram num trecho de aproximadamente 1.500 metros, que vai desde a linha de

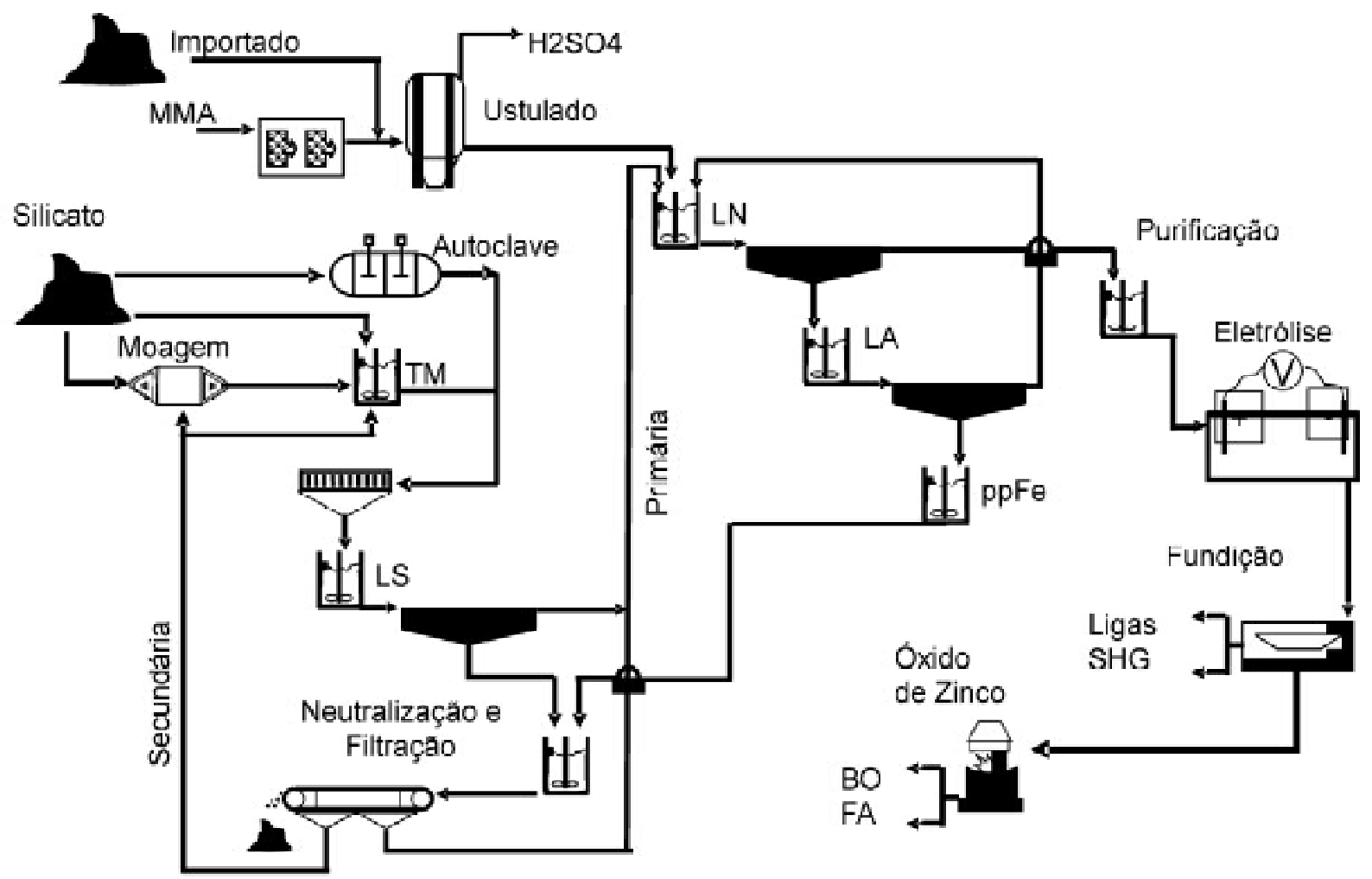

Fig 2: Processo usado pela CMM para o refino do Zn-silicatos/sulfetos

(Companhia Mineira de Metais - CMM, 2003).

transmissão de energia da CEMIG até as ilhas da Barra do Retiro. Os trabalhos de campo envolveram amostragens de água referentes ao verão de 2003 à 2006, segundo o Standard Methods for the Water and Wastewater (APHA 1992) e Guia de Coleta e Preservação de Amostras de água da CETESB (1988).

A amostragem de água foi efetuada em garrafas plásticas transparentes de $2 \mathrm{~L}$, previamente lavadas com $\mathrm{HNO}_{3}, 0,1 \mathrm{~N}$ e água destilada. No local de coleta mergulhou-se a garrafa a aproximadamente 15 a $30 \mathrm{~cm}$, com a boca do frasco contra a corrente, enchendo-a até a metade. Essa água foi utilizada para enxágüe e depois dispensada. Após essa operação, mergulhou-se o frasco, completando-o por inteiro, deixando apenas um pequeno espaço vazio para a homogeneização da amostra. As amostras de água foram e preservadas imediatamente com $\mathrm{HNO}_{3}$ em pH 2. O conteúdo de metais foi analisado pelo ICP-AES do Centro de Pesquisa do IGC/UFMG.

Paralelamente, no local da amostragem, foram 
medidos a condutividade e pH (aparelho Digimed, DM 20) da água.

Estes dados obtidos foram comparados aos resultados obtidos no mesmo período climático para os anos de 1991 (Fachhochschule München), e para se traçar daí, um perfil da evolução desta questão ambiental no local.

Os pontos de amostragens podem ser vistos na figura 3, e estes foram definidos pela localização a montante e a jusante da CMM, seus afluentes na área de entorno da CMM e suas confluências com o rio São Francisco.

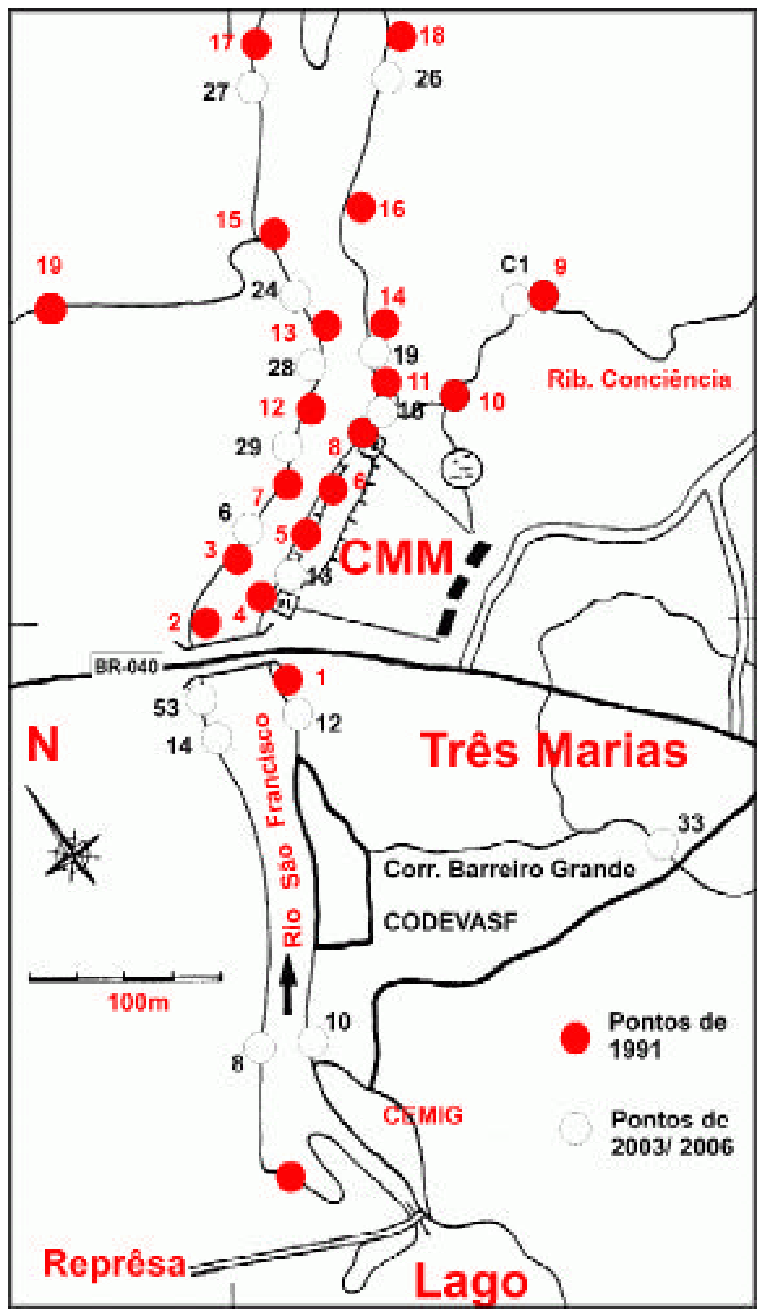

Figura 3 - Pontos de amostragem da água de 1991 e 2003/2006.

\section{RESULTADOS E DISCUSSÃO}

A descrição dos pontos de amostragem das 4 campanhas realizadas no rio São Francisco e dois de seus tributários que estão na área de influênciana CMM estão descritos a seguir no Quadro 1, e também a data de cada campanha de amostragem.

Nos QUADROS 2, 3, 4 e 5 são apresentados resultados de alguns metais pesados e ensaios de parâmetros físico-químicos nas águas superficiais investigada. Os valores que ultrapassaram os limites estabelecidos pela Legislação Ambiental, mais especificamente, a Resolução CONAMA 357/2005 encontram-se destacados em negrito.

Com base nos quadros 4 e 5, nota-se que o zinco esteve acima do padrão legal nos pontos amostrados das águas do córrego Barreiro Grande e no rio São Francisco, logo após o ponto de retorno da água, na margem esquerda e na confluência com o córrego Consciência, cujo valor está 25 vezes maior que o limite estabelecido pelo CONAMA 357/2005. A presença de zinco no córrego Barreiro Grande deve-se ao passivo ambiental existente no fundo do seu leito. Ressalta-se que, apesar da CMM ter interrompido o lançamento de rejeitos no córrego Barreiro Grande, há muitos anos, o zinco continua sendo disponibilizado para o rio São Francisco, por meio desse curso d'água. Segundo Mosetto (2003), nos EUA, e em várias outras partes do mundo, reconhece-se que, os contaminantes tóxicos presentes nos sedimentos dos rios, lagos, áreas alagáveis e corpos de água de regiões costeiras têm o potencial de desencadear uma degradação ambiental continuada mesmo nos casos onde a coluna d'água desses ambientes estejam dentro de critérios 'aceitáveis' de qualidade segundo os padrões vigentes. Reconhecese também que, sedimentos contaminados, podem causar impactos negativos à qualidade da água mesmo após a interrupção da descarga de efluentes ou abatimento completo das emissões ao corpo receptor.

Os resultados obtidos e apresentados nos Quadros 4 e 5 apontam um momento de contaminação das águas em período chuvoso, demonstrando que o grande caudal do rio São Francisco e sua respectiva capacidade de diluição, não estão sendo suficientes para reduzir as concentrações de zinco à valores abaixo do valor permitido pela legislação em determinados pontos. Porém em outros pontos monitorados isto não é verificado, demonstrando que este aumento fica restrito aos locais próximos ao corpo receptor de efluentes, que são os pontos 20 e 27, que localizam-se logo a jusante do ponto de retorno de água da CMM, margem direita e esquerda respectivamente. O elevado teor de zinco em alguns pontos pode ser explicado pelo ciclo deste metal no ambiente aquático. Primeiramente o zinco prendese, predominantemente, ao material suspenso antes de ser acumulado ao sedimento. No entanto, a ressolubilização em fase aquosa é possível, sob certas condições físico-químicas, como na presença de ânions solúveis, na ausência de matéria orgânica, minerais de argila e hidróxidos de ferro e manganês, baixo $\mathrm{pH}$ e salinidade aumentada.

Em relação ao de ferro, é um dos elementos mais importantes da constituição de solos e substratos rochosos, podendo ser considerados constituintes naturais das águas que drenam o território mineiro. Este elemento, juntamente com o alumínio e o manganês, estão em desacordo com o estabelecido pela legislação (Resolução 357/2005) em quase todo território mineiro. Contudo, os valores extremamente elevados denotam interferências das atividades antrópicas. Porém na área 
de estudo poucos pontos apresentaram valores mais altos do que a legislação preconiza, podendo estar os valores relacionados ao background da região para o elemento ferro.

Em relação à condutividade elétrica apesar da Resolução CONAMA 357/05 não dispor sobre valores para este parâmetro, segundo a CETESB, em geral, níveis superiores a $100 \mathrm{mS} / \mathrm{cm}$ indicam ambientes impactados, denotando principalmente a presença de sais dissolvidos nas águas. Valores altos, acima do padrão de referência, foram observados nas águas amostradas no rio São Francisco nos pontos 19 e 20, pontos

QUADRO 1 - Código e Descrição dos pontos de amostragem.

\begin{tabular}{|cl||}
\hline PONTO & \multicolumn{1}{c|}{ DESCRIÇĀO } \\
\hline 10 & Rio São Francisco, sob a linha de transmissão da Cemig, na margem direita do rio; \\
\hline 08 & Rio Săo Francisco, sob a linha de transmissão da Cemig, na margem esquerda do rio; \\
12 & Rio São Francisco, logo a jusante do córrego Barreiro Grande, na margem direita do rio; \\
14 & Rio São Francisco, logo a jusante do córrego Barreiro Grande, na margem esquerda do rio; \\
53 & Rio Săo Francisco, a montante da ponte da rodovia BR040; \\
33 & Córrego Barreiro Grande; \\
13 & Rio São Francisco, logo a jusante da ponte da rodovia BR040, na margem direita do rio; \\
06 & Rio São Francisco, logo a jusante da ponte da rodovia BR040, na margem esquerda do rio; \\
16 & Rio São Francisco, a jusante do dique da Barragem Velha da CMM, na margem direita do rio; \\
29 & Rio São Francisco, a jusante do dique da Barragem Velha da CMM, na margem esquerda do rio; rio; \\
19 & Rio São Francisco, a jusante do ponto de retorno da água da CMM, na margem direita do rio; \\
27 & Rio São Francisco, a jusante do ponto de retorno da àgua da CMM, na margem esquerda do rio; \\
20 & Rio São Francisco, a jusante do córrego Consciência, na margem direita do rio; \\
24 & Rio São Francisco, a jusante do córrego Consciência, na margem esquerda do rio; \\
C1 & Córrego Consciência; \\
26 & Rio São Francisco, próximo à ilha Barra do retiro, na margem direita do rio; \\
27 & Rio São Francisco, proximo à ilha Barra do retiro, na margem esquerda do rio; \\
\hline
\end{tabular}

de despejos industriais e/ou esgotos domésticos.

Em relação ao $\mathrm{pH}$, em cada campanha, pontos específicos apresentaram valores levemente mais ácidos, porém foi na $4^{\mathrm{a}}$ campanha que o $\mathrm{pH}$ tendeu localizados à jusante do local de retorno da água da CMM e da confluência como, córrego Consciência, evidenciando a presença de eletrólitos em solução. Logo, há interferências antrópicas, mediante lançamento

QUADRO 2 - Resultados de análises de zinco total, cádmio total e chumbo em águas superficiais e outros parâmetros- $1^{a}$ campanha - dez/2003.

\begin{tabular}{|c|c|c|c|c|c|c|c|c|c|c|c|c|c|c|c|c|c|c|c|}
\hline & & & & & & & & 3.3 & 13 & Cos & $16 \%$ & 20 & 19 & 23 & 21 & 34 & C.I & $x$ & 25 \\
\hline $\begin{array}{l}\text { Zinco Tolal } \\
\text { (mgl, } 7 . n)\end{array}$ & 0,18 & - & $<05$ & 41,5 & Ali,5 & 4,5 & - & - & $=$ & 4,5 & $-0,5$ & ant.5 & 40,5 & 45 & की,5 & 0,5 & - & 405 & 4,5 \\
\hline $\begin{array}{l}\text { Cadmio roul } \\
\text { (mgled) }\end{array}$ & 0,001 & $=$ & 405 & 40,5 & $=21,5$ & $\infty, 5$ & $=$ & $=$ & 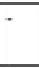 & 4,5 & $-40,5$ & 41,5 & 40,5 & 4,5 & dा,5 & 20,5 & $=$ & da, & $\infty, 5$ \\
\hline $\begin{array}{l}\text { Chumbo Fatal } \\
\text { (mgLP) }\end{array}$ & 0,03 & - & 40,5 & $\Rightarrow 0,5$ & $<0,5$ & 4,5 & - & - & . & 4,5 & 4,5 & 40,5 & 4,5 & 4,5 & $<0,5$ & 4,5 & - & 0,5 & 40,5 \\
\hline $\begin{array}{l}\text { Feno Iotal } \\
\text { (ms) L.Fe) }\end{array}$ & 0,3 & - & 0,65 & 0,66 & 0,61 & 0,75 & - & - & - & 0,59 & 0,72 & 0,98 & 0,79 & 0,61 & 0,75 & $\mathbf{0 , 7 7}$ & - & 0,97 & 1,62 \\
\hline $\begin{array}{l}\text { Condutividade } \\
\text { elétrica, } 25^{\circ} \mathrm{C} \\
\left(\text { mitem }^{-1} \text { ) }\right.\end{array}$ & $100^{*}$ & - & - & - & - & - & - & - & 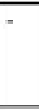 & - & - & - & - & - & - & - & - & - & - \\
\hline $\mathrm{pH}$ & 649 & - & 6,88 & 7,0 & 7,1 & 6,8 & - & - & $\cdot$ & 7,2 & 5,2 & 7,25 & 6,7 & 7,27 & 6,7 & 7,14 & - & 7,25 & 7,15 \\
\hline
\end{tabular}

a valores levemente baixos em diversos pontos. Isto pode ser explicado por estar a área localiza da numa região de precipitação pluviométrica elevada e de solo protegido por cobertura vegetal, existindo uma certa quantidade de $\mathrm{CO}_{2}$ derivado da atividade bacteriana que favorece a decomposição de organismos mortos, notadamente de vegetais gerando de ácidos húmicos e fúlvicos, e conseqüentemente, uma diminuição do pH (Baird, 2002). A dissolução do $\mathrm{CO}_{2}$ na água do solo irá depender da sazonalidade 
QUADRO 3 - Resultados de análises de zinco total, cádmio total e chumbo em águas superficiais e outros parâmetros- $2^{a}$ campanha-fev/2004.

\begin{tabular}{|c|c|c|c|c|c|c|c|c|c|c|c|c|c|c|c|c|c|c|c|}
\hline PRRÂMtRTE & 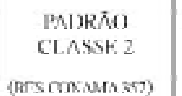 & f.ago & 10 & Q & $n$ & 14 & 53 & 33 & 13 & 6 & $k$ & 29 & 19 & 27 & 2) & 24 & $\mathrm{Cl}$ & 26 & 25 \\
\hline $\begin{array}{l}\text { Zinco Tomal } \\
\text { \{mgl. Zns }\end{array}$ & 0,18 & $<0,5$ & $<0,5$ & $<0,5$ & $<0,5$ & $<0,5$ & - & - & - & $<0,5$ & $<0,5$ & $<0,5$ & $<0,5$ & $<, 5$ & $<0,5$ & $<0,5$ & $<0,5$ & $<0,5$ & $<0,5$ \\
\hline $\begin{array}{l}\text { Cadmio lost } \\
\text { (mingl Cdi }\end{array}$ & 0,001 & $<0,5$ & - & $<0,5$ & $<0,5$ & $<0,5$ & - & - & $<0,5$ & $<, 5$ & $<0,5$ & $<, 5$ & $<0,5$ & $<, 5$ & $<0,5$ & $\infty 0,5$ & $<0,5$ & $<0,5$ & $<0,5$ \\
\hline $\begin{array}{l}\text { Chumbe Tolal } \\
\text { (mol Pb) }\end{array}$ & 0,03 & $<0,5$ & 20,5 & $<0,5$ & 80,5 & $<0,5$ & - & - & - & $<0,5$ & $<0,5$ & $<0,5$ & 40,5 & 40,5 & $<0,5$ & $<0,5$ & $<, 5$ & 80,5 & $<0,5$ \\
\hline $\begin{array}{l}\text { Ferro fotal } \\
\text { (mol, Fej }\end{array}$ & 0,3 & 0,28 & - & 0,79 & 0,76 & 0,52 & - & - & 0,89 & 0,80 & 0,81 & 0.78 & 0,94 & 0,78 & 1,22 & 0,75 & 1,66 & 0.93 & 0,81 \\
\hline $\begin{array}{l}\text { Condutividade } \\
\text { elétrica, } 25^{\circ} \mathrm{C} \\
\text { (msim }\end{array}$ & $100^{\text {st }}$ & 57,5 & - & 48,4 & 46,1 & 46,9 & - & - & 47,6 & 46,0 & 49,3 & 49,0 & 134,0 & 68,4 & 170,0 & 45,6 & 88,7 & 72,6 & 50,0 \\
\hline $\mathrm{pH}$ & 6 a 9 & 5,97 & - & 7,75 & 8,20 & 5,17 & - & - & 6,01 & 6,33 & 6,28 & 6,20 & 6,26 & 6,05 & 6,09 & 6,00 & 7,57 & 6,03 & 6,06 \\
\hline
\end{tabular}

QUADRO 4 - Resultados de análises de zinco total, cádmio total e chumbo em águas superficiais e outros parâmetros- $3^{a}$ campanha - out./2005 .

\begin{tabular}{|c|c|c|c|c|c|c|c|c|c|c|c|c|c|c|c|c|c|c|c|}
\hline MURAMFTROS & 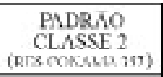 & I.ago & 10 & 08 & 12 & 14 & 53 & 33 & 13 & 06 & 16 & 29 & 19 & 27 & 20 & 24 & C1 & 26 & 25 \\
\hline $\begin{array}{l}\text { Zinen lobl } \\
\text { (mu/L Zn) }\end{array}$ & 0,18 & 0,011 & - & - & $\begin{array}{c}80,00 \\
5\end{array}$ & - & Qph158 & 1,385 & $\frac{700108}{7}$ & $\begin{array}{c}0,003 \\
1\end{array}$ & $\begin{array}{c}0,014 \\
5\end{array}$ & - & $\begin{array}{c}\text { W.1, } \\
\end{array}$ & $\begin{array}{l}-\infty, 00 \\
3\end{array}$ & $\begin{array}{c}0,060 \\
5\end{array}$ & $\begin{array}{l}20,00 \\
5\end{array}$ & 0,0229 & 0,0514 & 4,005 \\
\hline $\begin{array}{l}\text { Cadmio lati } \\
\text { (minglL Ca) }\end{array}$ & 0,001 & 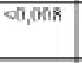 & - & - & $\begin{array}{l}-0,60 \\
*\end{array}$ & - & का, & $\begin{array}{c}40,00 \\
x\end{array}$ & $\frac{6000}{8}$ & $\begin{array}{c}\alpha_{0}, 50 \\
8\end{array}$ & $\frac{c 0,00}{8}$ & - & $\begin{array}{c}80,50 \\
x\end{array}$ & $\frac{6000}{8}$ & $\begin{array}{c}60,00 \\
8\end{array}$ & $\frac{\infty, 06}{8}$ & 6,008 & क,008 & क, 008 \\
\hline $\begin{array}{l}\text { Chumbo } \\
\text { Tulul (mgil.Pb) }\end{array}$ & 0,03 & - & - & - & - & - & - & - & - & - & 80,15 & - & सा, का & - & 60,05 & - & - & - & क, 05 \\
\hline $\begin{array}{l}\text { Ferro Tobal } \\
\text { (meg/L Fe) }\end{array}$ & 0,3 & 0,204 & $=$ & $=$ & $\begin{array}{c}4,037 \\
2\end{array}$ & $=$ & W.1389 & 2,87y & $\begin{array}{c}0,097 \\
7\end{array}$ & $\begin{array}{c}0,038 \\
11\end{array}$ & $\begin{array}{c}0,045 \\
5\end{array}$ & $=$ & $\begin{array}{c}\text { WuEA } \\
i\end{array}$ & $\begin{array}{c}0,045 \\
1\end{array}$ & $\begin{array}{c}0.053 \\
1\end{array}$ & $\begin{array}{c}0,032 \\
9\end{array}$ & 2,835 & 0,0438 & 0.0457 \\
\hline $\begin{array}{l}\text { Condutivid } \\
\text { ade } \\
\text { elétrica, } \\
25^{\circ} \mathrm{C} \\
\text { (msicm }^{-4} \text { ) }\end{array}$ & $100^{k}$ & 60,7 & $=$ & $=$ & 57,5 & $=$ & 50,9 & & 54,7 & $5,5,6$ & 54,2 &. & 51,0 & 47,2 & 49.2 & 47,2 & & 56,0 & 45 \\
\hline pH & 6 a9 & 6,7 & - & - & 6,3 & - & 6,4 & 7,0 & 6,6 & 6,8 & 6,0 & - & 6,9 & 6,8 & 59 & 6,3 & 6,0 & 6,7 & 6,0 \\
\hline
\end{tabular}

QUADRO 5 - Resultados de análises de zinco total, cádmio total e chumbo em águas superficiais e outros parâmetros- $4^{a}$ campanha - . março/2006

\begin{tabular}{|c|c|c|c|c|c|c|c|c|c|c|c|c|c|c|c|c|c|c|c|}
\hline MRKMIX & 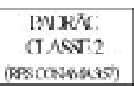 & lagn & in & 18 & 12 & 14 & 53 & 33 & 13 & 6 & $x$ & $\boldsymbol{z}$ & 19 & 27 & 201 & 24 & $\mathrm{Cl}$ & $2 i$ & 25 \\
\hline $\begin{array}{l}\text { Zinow Toul } \\
\text { (ngil. } / \mathrm{n} \text { ) }\end{array}$ & 0,18 & sion? & यक्कम & बकाल" & वस्क & mb? & $=$ & ब्राप? & 0 & कालm & बारुण & $4=0$ & niks & (48) & 4,453 & owo & onstg & $480 \mathrm{~m}$ & 4) \\
\hline $\begin{array}{l}\text { Cabivic Tol } \\
\text { ing LCh }\end{array}$ & 0,001 & याous & $460 \times x$ & anows & $40 \mathrm{dx}$ & stous & - & बारतल & sumos & - 00000 & $\sin \alpha$ & suaves & वाow: & $q 008$ & shous & 0,00 & quods & stax & souce \\
\hline $\begin{array}{l}\text { Chambo Tat } \\
\text { (myluh) }\end{array}$ & QqB & $400^{\circ}$ & 40,6 & $400^{\circ}$ & $400^{\circ}$ & $400^{\circ}$ & $400^{\circ}$ & 8,06 & 405 & 4006 & 8005 & 405 & $40 b^{\circ}$ & $\triangle 96$ & 400 & $400^{\circ}$ & $4 \omega^{\circ}$ & 4065 & 406 \\
\hline 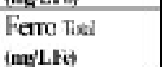 & a) & 8150 & - & - & 8182 & - & 005 & 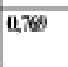 & कoक? & $0(\mathbb{1})$ & 0:455 & - & ât: & 40451 & Gus31 & 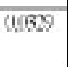 & and & 0438 & (1645? \\
\hline $\begin{array}{l}\text { Cordinitak } \\
\text { eletrica, } 25 \mathrm{C} \\
\text { nstar }^{-1}\end{array}$ & $100^{n}$ & 4 & 317 & 300 & 80 & n) & - & An 0 & 418 & Alys & 41,2 & 3000 & 423 & $\geqslant 5$ & 48,2 & 388 & 145 & 305 & $5 \times 9$ \\
\hline pH & $6 a 9$ & 6 & 56 & 64 & foll & 59 & $=$ & 60 & $\$ 8$ & 54 & 63 & & 50 & 59 & 56 & का & 5,9 & 54 & 59 \\
\hline
\end{tabular}

e da pluviosidade, o que poderá ser traduzido, que quanto menor a chuva maior a quantidade de $\mathrm{CO}_{2}$, assim, maior acidez. A $4^{\mathrm{a}}$ campanha foi realizada já em março, onde já ocorre um decréscimo da pluviosidade na região. Porém os valores do $\mathrm{pH}$ de maneira geral indicam uma boa diluição das águas e efluentes da CMM, e aboa capacidade de suporte do meio.

Observando-se os pontos amostrados em 1991, têmse valores bem mais elevados que os de hoje, devendo -se isto ao fato de não haver na CMM, naquela época, um cuidado com a deposição de seus efluentes. Naquela época todo efluente gerado na lavagem das áreas internas da fábrica, dos filtros e dos esgotos sanitários serem enviados a dois decantadores, onde era adicionado um agente floculante. Após este tratamento, o efluente era lançado no ribeirão Consciência (pontos 9 e 11). A lama proveniente dos filtros e em cuja composição encontra-se o zinco em maior proporção entre outros metais pesados, era lançada no terreno da fábrica através de uma correia transportadora, sem critérios adequados. A parte líquida percola pelo terreno, 
apresentando diversos pontos de ressurgência nas margens do rio, em frente à CMM ( pontos 5, 6 e 8). O efluente da eletrólise e a água de refrigeração da fábrica de ácido sulfúrico eram lançados diretamente no solo, sem qualquer tipo de tratamento, escoando para o rio São Francisco devido à topografia do terreno.

O zinco, cádmio e chumbo tiveram concentrações altas na área de influência da CMM, na margem direita do rio, ou seja, em pontos que recebem os efluentes diretos da CMM, até pontos mais afastados nesta mesma margem, mostrando que estes metais são transportados na forma solúvel, antes de se precipitarem junto com o sedimento.

Depois do córrego Consciência, o teor de zinco vai diminuindo gradativamente.

Ao compararmos o resultado da concentração do zinco de 1991 e das campanhas de 2003 à 2005, observamos que o ponto à jusante do córrego Consciência ainda continua com problemas, e que este elemento que naquela época apresentou um valor 22 vezes acima do limite permitido, em 2006 apresentou 25 vezes acima na margem direita e de 16 vezes passou para 3 vezes acima do limite na margem esquerda.

O cádmio foi encontrado em 1991 com valores elevados. Contudo, o resultado foi bastante diferente ao obtido nas campanhas de 2003 à 2006, cujos resultados estiveram todos abaixo do limite de detecção do aparelho. Tal fato é explicado pela redução na concentração dos sais pela diluição provocada pelas águas pluviais devido ao fator de diluição.

O cádmio é extremamente tóxico e potencialmente carcinogênico para o homem. Segundo WHO, 1992, apresenta grande mobilidade na água, podendo ser transportado por distâncias consideráveis, de até 50 $\mathrm{km}$ da fonte. Após seu lançamento e transporte, o cádmio tende a depositar-se no sedimento, permanecendo disponível à biota aquática por longos períodos, já que não é biodegradável.

O chumbo esteve presente em concentrações altas em 1991 em 3 pontos, todos na área de influência da CMM. Porém nas amostragens de 2003 à 2006 as concentrações foram baixas em todos os pontos. Todas as concentrações determinadas foram menores do que o limite preconizado pela legislação, tanto nos corpos d'água do rio São Francisco, como no Barreiro Grande. Ressalta-se que teores baixos de chumbo em meio hídrico, em período chuvoso, são aceitáveis, já que a maioria de seus compostos é praticamente insolúvel.

Deve-se lembrar que o chumbo é um metal ligado à poluição e é tóxico, bioacumulativo e sem função biológica conhecida, tanto para as plantas como para os seres humanos. Uma fração significativa de chumbo insolúvel pode ser incorporada em material particulado de superfície de escoamento, como íons sorvidos (adsorvidos e absorvidos) ou ainda na cobertura de superfície em sedimentos. A maior parte do chumbo é retida nos sedimentos e muito pouco é transportada nas águas de superfícies ou subterrâneas.

\section{CONCLUSÃO}

Ao se comparar o resultado da concentração do zinco de 1991 e das campanhas de 2003 à 2006, observase que o ponto à jusante do córrego Consciência ainda continua com problemas em relação às concentrações do zinco, e que este elemento que naquela época apresentou um valor 22 vezes acima do limite permitido, em 2006 apresentou 25 vezes acima na margem direita e de 16 vezes passou para 3 vezes acima do limite na margem esquerda. Outros metais, como o cádmio e o chumbo tiveram suas concentrações diluídas, podendo grande parte deste metal estar acumulado no sedimento, uma vez que possuem baixas solubilidades.

Pode-se concluir que a aplicação de formas mais adequadas de tratamento de efluentes pela CMM, levou a uma redução do nível destes metais nas águas superficiais, o que é indicado na interpretação dos dados levantados. Porém deve ser lembrado que ainda pode existir no local, metais nos sedimentos, uma vez que eles se precipitam junto a matéria orgânica, minerais de argila e óxidos e hidróxidos de ferro e manganês e que podem ser ressobilizados para a forma aquosa com mudanças das condições físico-químicas da água, por exemplo, mudança de $\mathrm{pH}$.

QUADRO 6-Resultados de análises de zinco, cádmio, alumínio e chumbo nas amostras das águas superficiais referentes a campanha de amostragem realizada em 1991 (Lundhamer, 1991).

\begin{tabular}{|c|c|c|c|c|c|c|}
\hline Ponto & Localização & pH & Zn (mg/L) & $\mathrm{Cd}(\mathrm{mg} / \mathrm{L})$ & $\mathrm{Al}(\mathrm{mg} / \mathrm{L})$ & $\mathrm{Pb}(\mathrm{mg} / \mathrm{L})$ \\
\hline 1 & & 6,3 & 0,299 & $<0,006$ & 0,44 & 0,036 \\
\hline 2 & & 5,6 & 0,062 & $<0,006$ & 0,44 & $<0,001$ \\
\hline 4 & & 5,3 & 105,314 & 0,885 & $<0,01$ & $<0,001$ \\
\hline 6 & & 5,3 & 7,92 & 0,065 & $<0,01$ & $<0,001$ \\
\hline 7 & & 5,3 & 0,084 & $<0,006$ & $\mathbf{0 , 5 0}$ & 0,030 \\
\hline 8 & & 5,3 & 0,253 & $<0,006$ & $<0,01$ & 0,034 \\
\hline 12 & & 5,3 & 2,750 & 0,040 & 1,10 & $<0,001$ \\
\hline 13 & & 5,3 & 2,926 & $\mathbf{0 , 0 2 3}$ & 0,44 & 0,030 \\
\hline 14 & & 5,3 & 3,960 & 0,009 & $<0,01$ & 0,034 \\
\hline 15 & & 5,3 & 0,047 & $<0,006$ & $<0,01$ & $<0,001$ \\
\hline 16 & & 5,3 & 1,650 & 0,018 & 0,40 & $<0,001$ \\
\hline
\end{tabular}




\section{BIBLIOGRAFIA}

American Public Health Association (APHA). 1992. Standard Methods for Examination of Water and Wastewater. $18 \mathrm{ed}$. Washington, EUA. p. 3-103;

Baird, C. 2002. Química Ambiental - Bookman, 2 ed. Porto Alegre;

CETEC, 1980. Estudos de Metais Pesados no Estado de Minas Gerais. Relatório Final. Belo horizonte. 151p;

CETEC, 1983. Diagnóstico Ambiental do Estado de Minas Gerais. 1v. Belo Horizonte. $158 \mathrm{p}$;

CETESB, 1988. Guia de coleta e preservação de amostras de água. 1 ed. São Paulo. 149p;

Chiavegatto, J. R. S. 1992. Análise das Sequiências Tempestíticas da Formação Três Marias ( Proterozóico Superior) na porção meridional da Bacia do São Francisco. Dissertação de mestrado, curso de pós-graduação em Geociências da UFOP, Ouro Preto, Mg, 216p;

Companhia Mineira de Metais-CMM. 2003. Relatório de Desempenho Ambiental - RADA - Votorantin Metais. 114p;

CONAMA, 1986. Conselho Nacional do Meio Ambiente. Resolução CONAMA nº20 de 18/06/86;
CONAMA, 2005. Conselho Nacional do Meio Ambiente. Resolução CONAMA n³57 de 17/03/05;

Euclydes, H. P \& Ferreira, P. A. 2001. Bacia do Alto São Francisco. Recursos Hídricos e Suporte Tecnológico a projetos Hidroagrícolas. Ruralminas. Viçosa, MG, 236p;

Forstner, U. \& Wittmann, G. T. W. 1981. Metal Pollution in the Aquatic Environment. 2ed. Berlim. Springer- Verlag. 486 p.;

GREENPACE, 2002. Crimes Ambientais Corporativos no Brasil. Disponível: http://www.greenpeace.org.br.

Jardim, W. F. 1983. Metais Pesados, um dano irreparável. Revista Brasileira de Tecnologia. Brasília. v 14(2):41-45;

Macedo, J. A B. 2002. Introdução à Química Ambiental- Juiz de Fora- MG. 1ed. 487p.

Menezes Filho, N. R.; Matos, G. M. M.; Ferrari, P. G. 1978. Projeto Três Marias. Belo Horizonte. Convênio DNPM/ CPRM. 338 p.

Mozeto, A A 2003. Critérios de Qualidade de Sedimentos (LQS) para Metais Pesados: Fundamentos Teóricos e Técnicos para implementação do laboratório de Biogeoquímica Ambiental - DQ - UFSCar/ São Carlos, SP.

WHO - World Health Organization. 1992. Cadmium. Geneva: WHO: Environmental Health Criteria 134p. 
